\title{
Evaluating the Impact of Regional Marketing Projects on the Development of Regions from Different Stakeholder Perspectives
}

\author{
Kim-Kathrin Kunze ${ }^{1}$, Hanna Schramm-Klein ${ }^{2}$ \\ ${ }^{1}$ Department of Marketing, University of Siegen, 57068 Siegen, Germany \\ ${ }^{2}$ Department of Marketing, University of Siegen, 57068 Siegen, Germany
}

\begin{abstract}
In the competition for economically attractive stakeholders, regions have to implement strategies to gain and adhere those interest groups. Empirical studies concerning the migration motivations show that it is not only labor market but also soft locational factors of the social environment, nature and landscape that are of high importance: A majority of the population is willing to move or rather stay at a special place because of such soft locational factors. This study examines the impact of regional marketing projects on the development of regions from the perspectives of inhabitants and tourists as well as general attributes to measure a region's attractiveness from the perspective of high potentials. We argue that those projects that fit to the region and its unique selling propositions contribute to positioning and building location brand value. We show that projects have a socio-economic effect on the attitude towards regions and contribute to building location brand value. An analysis of group differences shows that the project influence on the region and region attractiveness are perceived in significantly different manner depending on the knowledge level of the stakeholder group. Consequently, one should increase the awareness of marketing activities and regions and focus on soft locational factors while establishing and positioning a region brand.
\end{abstract}

\section{Introduction}

The competition between regions and cities concerning attractive stakeholders, e.g. investors, inhabitants, tourists and human capital increases [1]. Demographic change and the urbanisation of the younger generation cause an aging and decline of the population as well as an increasing skill's shortage. Especially rural areas and old working-class regions have to implement strategies to gain and adhere inhabitants, manpower and external stakeholder groups. These regions started to develop proactive and responsive strategies to communicate their potential for increasing investments and quality of life [2]. Empirical studies concerning the migration motivations show that besides the labor market the soft locational factors of the social environment, nature and landscape are of high importance: A majority of the population is willing to move or rather stay at a special place because of such soft locational factors. Regional marketing projects shall increase the attraction of a region and thereby attract different stakeholder groups [2-4]. However, the effectiveness of establishing and promoting destination uniqueness has declined dramatically during the past few years. Many destinations rely on the promotion of similar quality characteristics such as scenery, history and 
culture and lose sight of the relevant and unique destination attributes [5]. In this paper, we address the issue of regional brand image. We argue that regional marketing projects that fit to the region and its unique selling propositions contribute to positioning and building location brand value. Most studies focus on tourism marketing alliances and possible marketing activities such as communication and campaign design which could strengthen a region, but almost no study analyses the influence of existing regional marketing projects. Usually, the investigations do not differ between diverse stakeholder perspectives and reproduce only in rare cases the whole process of attitude and behavior formation. Therefore, the aim of this study is to fill these gaps in empirical research and to investigate how to positively influence the perception, attitude and behavior towards a region. We focus our research on a specific regional marketing project - a wildlife conservation project - that can be understood as a soft locational factor to increase the value of leisure and nature of a region.

\section{Background}

A region becomes a recognizable and recallable location for the target group with the help of regional marketing which is used to develop regions and build relationships between the region, its market partners and target groups. It supports a strategic positioning and profiling of a region within the competitive environment between regions wherefore it includes the analysis, planning, implementation and control to identify and realize site-related factors, which provide competitive advantages to target groups [6]. Therefore, regional marketing has to fit with the requirements of the target groups with regard to cultural, demographic and economic relations [6].

Altered global and local challenges shifted the priorities in the field of regional marketing: Global challenges concern the macroenvironment of a region, e.g. as a result of globalization; local challenges relate to the microenvironment, thus, changes inside of a region such as demographic change. These changes force regions to identify and improve those factors that form their region attractiveness to gain and adhere the required stakeholders with whom the continuity of the region may be ensured. Regions have to adjust their profile to the particular needs of their interest groups to make them want to migrate, visit and stay in the region in which they are needed to limit the results of demographic change and provide manpower that ensures future economic security. A region's attractiveness reflects the opinions, beliefs and emotions that individuals hold about a region's perceived ability to provide satisfaction in relation to one's specific needs [7]. It can be understood as the result of a comparison process relating to the relative importance of individual benefits and the perceived ability of the region to deliver these individual benefits. It is incidental that the stronger the belief in a region and its satisfaction of individual needs are, the more attractive that region will be and the more likely it will be selected as a potential domicile, place of work, or travel destination. For all types of relations towards a region, the region represents a package of facilities and services consisting of various multidimensional attributes that altogether determine its attractiveness to a particular individual. Some individuals want to stay and live in the region because of these attributes, others will be drawn away from their homes and visit or move to the region [7].

Regional marketing projects in particular focus on the conception and establishment of strong local brands and need to consider the diverse demand of a region's different stakeholders. Previous literature has shown that regional marketing activities influence a region's image and associated behavior such as a visiting purpose in a positive way. Regions have to differentiate between two target group orientations: a) internal stakeholders are mainly the inhabitants as well as intraregional service providers and decision-makers in the fields of economy, science, education, culture, politics and leisure; b) external target group orientation alludes for instance to potential inhabitants, investors, companies, manpower and tourists [6-8].

In this study, we focus our research on a specific regional marketing project - a wildlife conservation project - that can be understood as a soft locational factor to increase the value of leisure and nature of a region. The special feature of this project is its location: Imbedded in the rural area of Bad Berleburg in North Rhine-Westphalia, Germany, it is very close connected to the supervising district Siegen-Wittgenstein which itself consists of two regional parts. An urban city builds the center 
of reference which is surrounded by many rural villages and towns. The relationship between the project and the involved cities and regions is full of interdependencies and raises expectations in the context of social, demographic, touristic and economic development within all stakeholder groups. This project includes a socioeconomic component which influences different stakeholders like inhabitants and tourists. Within the group of inhabitants, acceptance should be build because they live and stay close to the project and are confronted with it in their daily live. It is necessary to inform and integrate them in the process of establishing such a regional marketing projects. Tourists should be attracted with the help of diverse marketing activities and image campaigns to increase the knowledge of the project and region as tourist destinations.

\section{Conceptual Background and Research Design}

We base our study on these general aspects of regional marketing with the focus on how regional marketing projects can help building strong regional brands both for internal as well as external stakeholders. Our aim is to investigate how to positively influence the stakeholder's perception, attitude and behavior towards a region, regional loyalty and regional image. With our study we consider the two major problems regions have to deal with: (1) informational problems based on the lack of integration of different stakeholders in the decision process and (2) informational problems based on perceptions and attitudes towards a region and its service offers of different stakeholders. On the supply side, a region tries to differentiate and separate itself from others by profiling its economic and living space. On the demand side there are different stakeholders with different needs and interests. Taking these groups into account, a region has to consider different views on itself: Internal stakeholders are 'locals' that know the region from their own perception and opinions, relying on their own impressions and experiences, whereas external stakeholders have a distorted view, which often arises from secondary information. Regions or destinations pursue the goal of increasing their stakeholders' awareness level and thereby try to enhance the attitude towards their service offer and to improve their images [8]. The specific objectives of our study are therefore to contribute to the knowledge on the impact of regional marketing projects on the development of regions and destinations from the perspective of (a) internal stakeholders and (b) external stakeholders.

The conceptual framework of our study is based on the theory of reasoned action (TRA) that suggests that an individual's attitude towards the behavior and subjective norms form and influence the behavioral intention. Individuals and groups make decisions with respect to their own attitude towards that behavior and take account of the social desirability [9]. Transferred to our research context, we propose that regions have to build a consistent regional image to avoid a lack of integration of supply and demand side tasks. According to TRA, attitudes are formed based on consumer evaluation of the destinations' characteristics [10-12]. They are regarded key antecedents in attitude formation. We therefore propose:

\section{H1: Consumer evaluation of a regional marketing project has a positive impact on the attitude towards this specific project.}

For that reason, regions have to identify their target groups and have to align their supply with their stakeholders' needs. Concerning these target group orientations, regions have to consider different perspectives on themselves. Locals or visitors know the region and/or the regional marketing project and can rely on their own impressions and experiences, whereas external stakeholders posses secondary information.

Attitude towards a region reflects individual mental pictures and associations that individuals hold with regard to a specific region, to delineate it from competing regions. Besides this cognitive dimension, however, attitudes also hold an affective dimension that includes a regional bonding, i.e. internal stakeholders such as inhabitants identify themselves with the region and external stakeholders develop interest in the region and its offers. If a region is able to produce positive attitudes, according to TRA this should result in positive behavioral intentions towards the region. For internal 
stakeholders, this might mean a decrease in migration and an increase in commitment with the region. For external stakeholder, for example, this would lead to increasing tourism, investments and migration into the region and would state an incentive for businesses to locate in the region.

Regional marketing projects are embedded in the specific region. Thus, there should be an intercorrelation of images both of the region itself and the regional marketing project. Attitude is an effective predictor of participation and satisfaction. We assume that individuals transfer their positive or negative attitude from one object to another, providing that there is a fit between the subject matters [13-14]. Thus, in addition to the effect of the individual's evaluation of a regional marketing project, attitude formation towards these projects is based on the general attitude that consumers hold towards a region. However, because of the nested constellation of regional marketing projects as elements that altogether form the attitude towards a region, we also expect that the attitude towards the regional marketing project influences the attitude towards the region. We therefore propose:

\section{H2a: The attitude towards a region influences the attitude towards a regional marketing project in a positive way.}

$H 2 b$ : The attitude towards a regional marketing project influences the attitude towards a region in a positive way.

Following TRA, perceptions and attitudes of the attractiveness of objects may lead individuals to develop an attachment to it. With respect to regional marketing, this implicates that attractive marketing activities such as regional marketing projects cause commitment with the project and lead to positive behavioral intentions with regard to the regional marketing project [15]. However, we also suppose an influence of social norm and therefore assume, that individuals form their attitude towards regions and regional marketing projects with respect to social desirability. We expect them to behave in a way that matches with their attitude towards this behavior and subjective norms [9].

This is in line with TRA, we therefore propose that an individual's attitude towards a regional marketing project acts as a predictor of its satisfaction which affects the behavioral intention [13, 16]. With respect to regional marketing, this implicates that attractive marketing activities such as regional marketing projects cause commitment with this project and lead to positive behavioral intentions with regard to the regional marketing project [15]. However, we also suppose an influence of social norm and therefore assume, that individuals form their attitude towards regions and regional marketing projects with respect to social desirability. We expect them to behave in a way that matches with their attitude towards this behavior and subjective norms [9]. This is in line with TRA, we therefore propose that an individual's attitude towards a regional marketing project acts as a predictor of its satisfaction which affects the behavioral intention [13,15-17].

\section{H3: The attitude towards a regional marketing project has a positive influence on the behavioral intention with regard to this project.}

To test our hypotheses, we conducted a series of consumer surveys in a central German region. As environmental stimuli we included a) a region's general attributes such as quality of life, labor market, leisure time activities and $\mathrm{b}$ ) a wildlife conservation project (the reintroduction of European bisons to the wild) as a specific marketing project within the region that offers a range of services that fit to the region like hiking, walking, etc. A prestudy and focus groups showed that there is a fit between the considered region and the corresponding regional marketing project.

Our first study was the start of a long-term study to analyze the changes in evaluation, attitude formation and behavior. This first investigation was executed during the establishment of the regional marketing project. Therefore, we included intentional behavior as outcome variable. The second investigation was executed after the opening of the project which entails the measurement of real behavior.

Our first quantitative consumer survey was conducted following a broad qualitative study, consisting of 26 in-depth focus group discussion which were conducted in the observed region. The 
sample of Study I $(\mathrm{N}=676)$ represents the demographic structure of the region, 49,9\% were male and $50,1 \%$ female inhabitants. To avoid problems of social desirability bias in the measures, we administered questionnaires to consumers in the pedestrian areas of 26 cities and villages in the region, conducted face-to-face interviews ( $78 \%$ of respondents) and an online survey (22\% of respondents). In Study II, we administered it to 141 consumers in the region under review, who had not answered it in the first period, and 98 consumers outside of the observed region $(\mathrm{N}=196)$ to detect possible differences between an internal and external sample. This internal sample showed the same demographic structure as in Study I and the external sample was adapted to represent demographics of Germany.

In this study four main constructs were analysed both for the region and for the regional marketing project: perception/awareness, image, attitude and behavioral intention. The items were adapted from previous studies. To measure perception or awareness, we adapted a 3-item scale from Bigné, Sànchez \& Sànchez [15], such as "What do you know about the region?". Attitude was measured with 10 items from Batra and Ahtola [18], e.g. useful, nice, safe. To analyse the behavioral intention, we used items such as "I would recommend the city to my family and friend" [13]. We used almost the same items to analyse the perception, attitude, image and behavioral intention towards the region marketing project to see if they fit together. All constructs are measured with a seven point scale ranging from strongly disagree (1) to strongly agree (7).

\section{Analysis and Results}

Measure validation and model testing for the model were conducted using Smart PLS. Because we expected bidirectional effects between our latent constructs, we conducted two separate pathways each with one hypotheses system (following suggestions of [19]).

The results for Study I are presented in Table 1 and Table 2. The endogenous variables are wellexplained by the endogenous variables. The significant path coefficient of .768 with high effect size of $\mathrm{f}^{2}=1.527$ shows that the evaluation of the regional marketing project has a very strong influence on the attitude towards the region. Thus, we can confirm $\mathrm{H} 2 \mathrm{~b}$. In contrast, the attitude towards the region has no substantial influence on the attitude towards the project. H2a, therefore, cannot be confirmed. Thus, the better evaluation of the regional marketing project, the better is the attitude towards the project $(\beta=.768)$. A positive attitude towards the project induced the consumers more likely to visit it $(\beta=0.719)$. Hypotheses $\mathrm{H} 1$ and $\mathrm{H} 3$ are supported by our data, however, we cannot find support for $\mathrm{H} 2 \mathrm{~b}$. A possible reason for this might be that the regional marketing project was not yet opened during the first data collection. This result may change within the second questioning.

Table 1

\begin{tabular}{|c|c|c|c|c|c|}
\hline $\begin{array}{l}\text { exogenous, latent } \\
\text { variables }\end{array}$ & endogenous variables & $\beta$ & $\mathrm{f}^{2}$ & $\mathrm{R}^{2}$ & $\mathrm{Q}^{2}$ \\
\hline $\begin{array}{l}\text { image of regional } \\
\text { marketing project }\end{array}$ & \multirow{2}{*}{$\begin{array}{l}\text { attitude towards } \\
\text { regional marketing } \\
\text { project }\end{array}$} & $0.768 * * *$ & 1.527 & \multirow{2}{*}{0.652} & \multirow{2}{*}{0.462} \\
\hline attitude towards region & & $0.105 * *$ & 0.028 & & \\
\hline $\begin{array}{l}\text { attitude towards } \\
\text { regional marketing } \\
\text { project }\end{array}$ & $\begin{array}{l}\text { behavioral intention towards the } \\
\text { regional marketing project }\end{array}$ & $0.719 * * *$ & & 0.517 & 0.510 \\
\hline
\end{tabular}

In our second path model, we reveal that the influence of the attitude towards the regional marketing project has no explanatory power for the attitude towards the region $\left(\mathrm{R}^{2}=.120\right)$, but the path coefficient indicates that the relation between the two constructs is substantial $(B=.347)$. Hypothesis H2b can be supported. The Stone-Geisser-Criterion which assesses the predictive quality of the model indicates a satisfactorily model specification [20]. 
Table 2

\begin{tabular}{|c|c|c|c|c|}
\hline exogenous, latent variables & endogenous variables & $\beta$ & $\mathrm{R}^{2}$ & $\mathrm{Q}^{2}$ \\
\hline $\begin{array}{l}\text { image of regional marketing } \\
\text { project }\end{array}$ & $\begin{array}{l}\text { attitude towards regional } \\
\text { marketing project }\end{array}$ & $0.801 * * *$ & 0.642 & 0.456 \\
\hline $\begin{array}{l}\text { attitude towards regional } \\
\text { marketing project }\end{array}$ & attitude towards region & $0.347 * * *$ & 0.120 & 0.074 \\
\hline $\begin{array}{l}\text { attitude towards regional } \\
\text { marketing project }\end{array}$ & $\begin{array}{l}\text { behavioral intention towards } \\
\text { the regional marketing project }\end{array}$ & $0.719 * * *$ & 0.517 & 0.514 \\
\hline
\end{tabular}

In Study II, we distinguish between the internal $(\mathrm{N}=141)$ and the external sample $(\mathrm{N}=98)$.

Table 3

\begin{tabular}{|c|c|c|c|c|c|c|c|}
\hline \multirow[b]{2}{*}{$\begin{array}{l}\text { exogenous, latent } \\
\text { variables }\end{array}$} & \multirow[b]{2}{*}{ endogenous variables } & \multicolumn{2}{|c|}{ internal sample } & \multicolumn{4}{|c|}{ external sample } \\
\hline & & $\beta$ & $\mathrm{R}^{2}$ & $\mathrm{f}^{2}$ & $\beta$ & $\mathrm{R}^{2}$ & $\mathrm{f}^{2}$ \\
\hline $\begin{array}{l}\text { image of regional } \\
\text { marketing project }\end{array}$ & $\begin{array}{l}\text { attitude towards } \\
\text { regional marketing }\end{array}$ & $0.796^{* * *}$ & 0.681 & 1.793 & $0.683^{* * *}$ & 0.597 & 0.925 \\
\hline attitude towards region & project & $0.084^{\mathrm{ns}}$ & & 0.019 & $0.169 *$ & & 0.057 \\
\hline $\begin{array}{l}\text { attitude towards } \\
\text { regional marketing } \\
\text { project }\end{array}$ & $\begin{array}{l}\text { behavioral intention } \\
\text { towards the regional } \\
\text { marketing project }\end{array}$ & $0.750^{* * *}$ & 0.563 & 0.514 & $0.660 * * *$ & 0.436 & 0.514 \\
\hline
\end{tabular}

Table 4

\begin{tabular}{llcccc}
\hline & & \multicolumn{2}{c}{ internal sample } & \multicolumn{2}{c}{ external sample } \\
\cline { 3 - 5 } exogenous, latent variables & endogenous variables & $\beta$ & $\mathrm{R}^{2}$ & $\beta$ & $\mathrm{R}^{2}$ \\
\hline $\begin{array}{l}\text { image of regional marketing } \\
\text { project }\end{array}$ & $\begin{array}{l}\text { attitude towards regional } \\
\text { marketing project }\end{array}$ & $0.821^{* * * *}$ & 0.674 & $0.758^{* * * *}$ & 0.575 \\
\hline $\begin{array}{l}\text { attitude towards regional } \\
\text { marketing project }\end{array}$ & attitude towards region & $0.329^{* * *}$ & 0.108 & $0.472^{* * *}$ & 0.223 \\
\hline $\begin{array}{l}\text { attitude towards regional } \\
\text { marketing project }\end{array}$ & $\begin{array}{l}\text { behavioral intention towards } \\
\text { the regional marketing } \\
\text { project }\end{array}$ & $0.750^{* * *}$ & 0.563 & $0.660^{* * *}$ & 0.435 \\
\hline$* * * \mathrm{p} \leq 0.001 ; * * \mathrm{p} \leq 0.01 ; * \mathrm{p} \leq 0.05 ;$ n.s. $\mathrm{p}>0.05$ & & & & \\
\hline
\end{tabular}

Generally, the results show that the project is significantly better known in the internal sample. In the analysis of the data subsets with the moderator variable 'regional affiliation', it is to accentuate that the path coefficient $\beta$ of the relation between the image of the project and the attitude towards the project in the internal sample is higher than in the external one. The effect size of the influence of regional project evaluation on the attitude towards the regional project is also stronger than in the external sample. Thus, there are differences in awareness of the project and otherwise that the awareness has an influence on the image.

Although in the internal sample there is higher knowledge with regard to the project, the attitude towards it is significantly higher than in the external sample. However, a t-test shows that the path coefficient and $\mathrm{R}^{2}$ in the external sample are significantly higher than in the internal sample $\left(\beta^{\text {internal }}=0.329 ; \beta^{\text {external }}=0.472 ; \mathrm{R}^{2 \text { internal }}=0.108 ; \mathrm{R}^{\text {2external }}=0.223\right)$. Thus, these results show that there is a different impact of regional marketing projects on internal and external stakeholders.

The comparison of the two path models reveals significant differences, especially with regard to $\mathrm{H} 2 \mathrm{~b}$ in path model II. Differences in consideration of the significance of the path relations exist in 
path model I, whereas the influence of the construct 'attitude towards region' on the construct 'attitude towards the regional marketing project' is not significant in the internal sample, however it is in the external one. A possible reason for this effect may be that some respondents of the internal sample indicated that they do not associate the regional project with the region. Nevertheless hypothesis $\mathrm{H} 2 \mathrm{~b}$ shows that the attitude towards the project influences the attitude towards the region significantly positive. This effect is considerably and significantly higher in the external sample.

\section{Conclusion and Implications}

This study examines the impact of regional marketing projects on the development of regions and destinations from the perspectives of inhabitants and tourists. While previous studies focused on migration motivations and soft locational factors, this study shows that regional marketing projects have a significantly positive effect on the attitude towards regions. Our results of the PLS models show that the behavioral intention is significantly and substantially influenced by the attitude towards this project. This attitude is in turn significantly and substantially influenced by the evaluation of the project's characteristics. However, the comparison of the region-internal and region-external respondent groups shows that perception and evaluation of the regional marketing project depend on the awareness of the project. Consequently, regional marketing managers should increase the awareness of marketing activities within the different stakeholder groups.

The most important result for regional marketing managers is the positive effect of the attitude towards a marketing project on the attitude towards a region. This can be understood as an indication that such projects have positive socio-economic effects on the attitudes towards a region. An analysis of group differences provides the result that the project influence on the region is more significant within an external sample. This implicates that regional marketing should focus on soft locational factors while establishing and positioning a region brand and corresponding strategies.

\section{References}

1. R.L. Florida, The flight of the creative class: The new global competition for talent, HarperBusiness, HarperCollins, NY (2008).

2. $\quad$ R. Paddison, City Marketing, image reconstruction and urban regeneration, Urb. St., 30, 2, 339349 (1993)

3. P. Pellenbarg, W. Meester, Regional Marketing to change regional images: The examples of the Groningen Province Campaign, ESRP, 16, 1, 23-39 (2009)

4. K. Knickel, H. Renting, Methodological and conceptual issues in the study of multifunctionality and rural development, Sociol. Rural., 40, 4, 512-528 (2009)

5. C. Blain, S.E. Levy, J.R.B. Ritchie, Destination branding: Insights and practices from destination management organizations, JTR 43, 3, 328-338 (2005)

6. M. Kavaratzis, Place Branding : A review of trends and conceptual models, MR 5, 4, 329-342 (2005)

7. Y. Hu, J.R. Ritchie, Measuring destination attractiveness: A contextual approach, JTR 32, 25, 25-34 (1993)

8. L. Birgit, Image segmentation : The case of a tourism destination, JSM 15, 1, 49-66 (2001)

9. M. Fishbein, I. Ajzen, Understanding attitudes and predicting social behaviour, Prentice Hall, Englewood-Cliffs, NJ (1980).

10. C.B. Castro, E.M. Armario, D.M. Ruiz, The influence of market heterogeneity on the relationship between a destination's image and tourist's future behaviour, TM 28, 175-187 (2007)

11. C.F. Chen, D.C. Tsai, How destination image and evaluative factors affect behavioral intentions, TM 28, 1115-1122 (2007)

12. A. Beerli, J.D. Martìn, Tourists' characteristics and the perceived image of tourist destinations: A quantitative analysis - a case study of Lanzarote, Spain, TM 25, 623-636 (2004) 
13. T.H. Lee, Ecotourism behavioral model of national forest recreation areas in Taiwan, Int. Forestry Rev. 9, 3, 771-785 (2007)

14. M.G. Ragheb, R.L. Tate, A behavioural model of leisure participation, LS 12, 1, 61-67 (1993)

15. J.E. Bigné, M.I. Sanchez, J. Sanchez, Tourism image, evaluation variables and after purchase behavior: Interrelationship, TM 22, 6, 607-616 (2001)

16. I. Ajzen, The theory of planned behavior, organization behavior and human decision processes, 50, 179-211 (1991)

17. I. Ajzen, B.L. Driver, Application of the theory of planned behavior to leisure choice, JLR 24, 3, 207-240 (1992)

18. R. Batra, O.T. Ahtola, Measuring the hedonic and utilitarian sources of consumer attitudes, Marketing Letters 2, 2, 159-170 (1990)

19. M. Wetzels, G. Odekerken-Schröder, C. van Oppen, Using PLS path modeling for assessing hierarchical construct models, Mis Quarterly 33, 1, 177-195(2009)

20. C. Fornell, J. Cha, Partial Least Squares, Blackwell Publishers, Cambridge, MA (1994) 